\title{
Percutaneous transcystic cholangioscopy-guided electrohydraulic lithotripsy in a patient with altered surgical anatomy
}

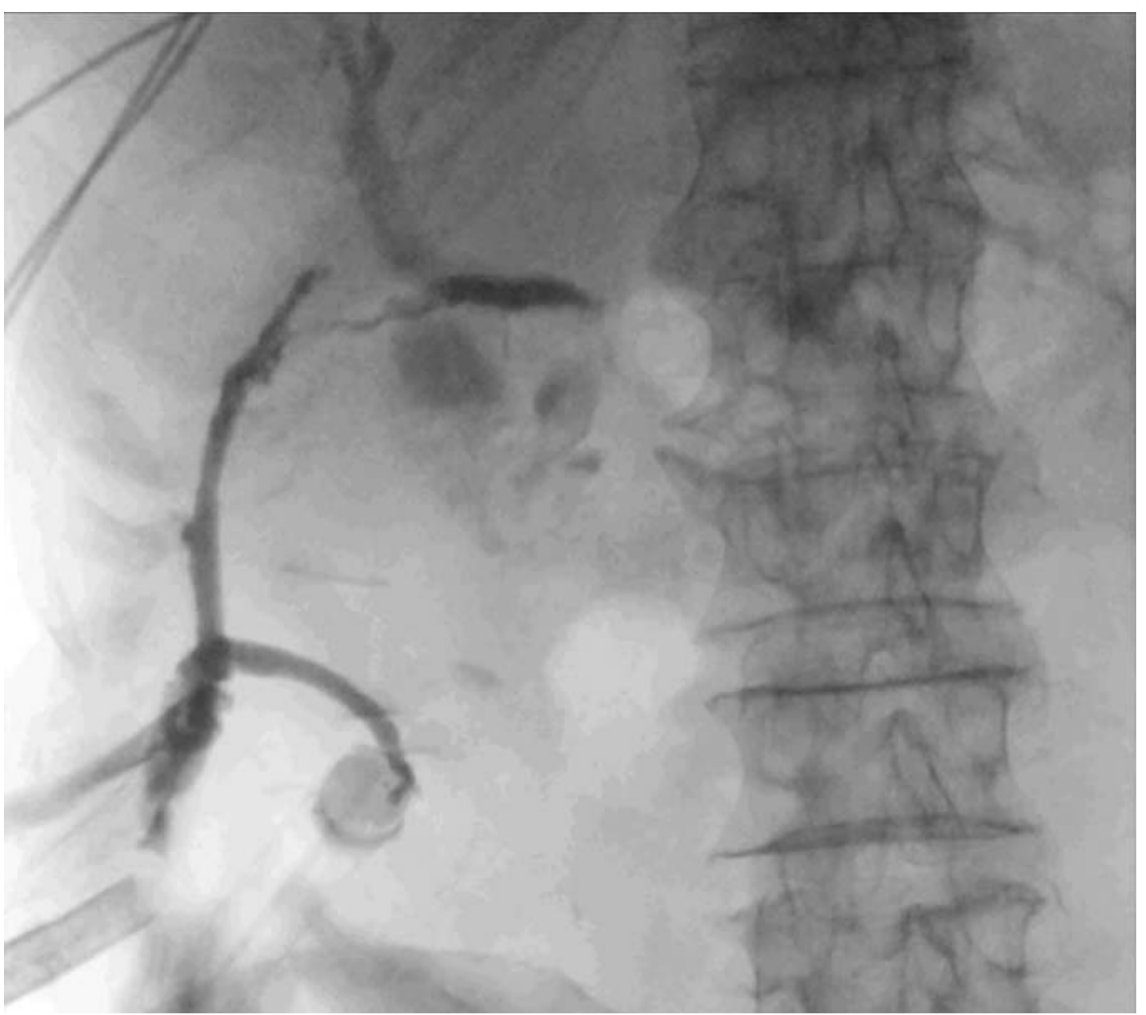

- Fig. 1 Fluoroscopic image confirming persistence of the percutaneous tract, which is tortuous and narrowed in the proximal part.

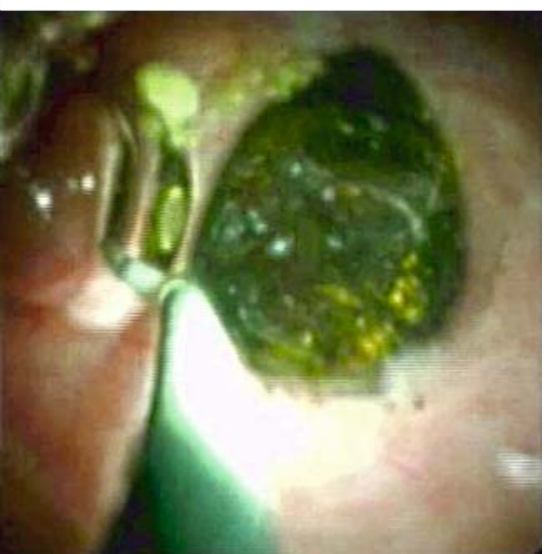

Fig. 3 Cholangioscopic image of the stone located in the distal part of the common bile duct.

A 68-year-old man with a history of Roux-en-Y partial gastrectomy for gastric cancer and pancreatic enucleation for a

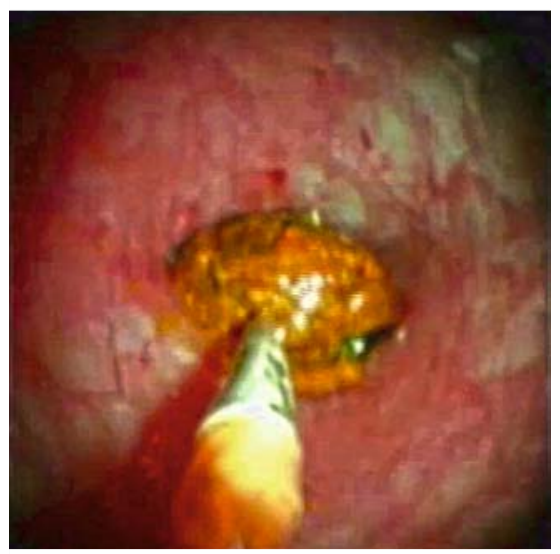

- Fig. 4 Cholangioscopic image during electrohydraulic lithotripsy of the stone.

somatostatin-producing neuroendocrine tumor underwent urgent open cholecystectomy due to acute cholecystitis. In-

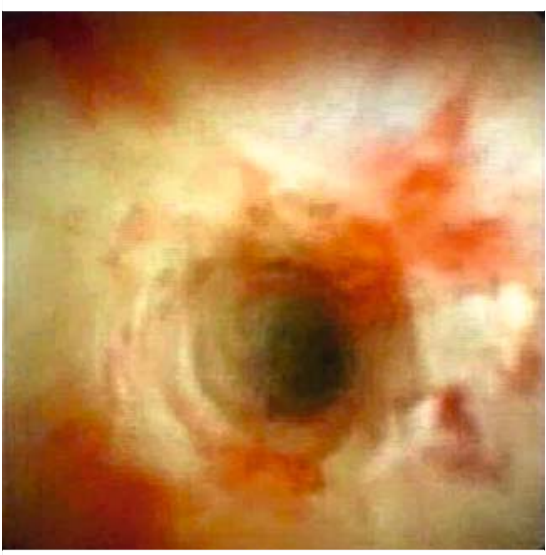

- Fig. 2 Cholangioscopic image of the percutaneous tract during access to the common bile duct.

traoperative choledochoscopy showed a common bile duct (CBD) stone which could not be removed. A transcystic Nelaton tube was placed. One week later, cholangiography confirmed the $10-\mathrm{mm}$ CBD stone was still present. The tube was left in place to allow maturation of the tract for a further procedure, but 20 days later it was accidentally displaced. As percutaneous biliary drainage persisted, the patient was referred to us to try percutaneous transcystic cholangioscopy-guided electrohydraulic lithotripsy. Contrast instilled directly into the percutaneous access confirmed persistence of the tract, which was tortuous and narrowed in the proximal part ( $\mathbf{F i g . 1}$ ). Guidewire passage into the CBD was difficult ( Fig.2) and was only achieved under contrast guidance with looping of the guidewire and single-operator cholangioscope (Spyglass DS II) assistance. Passage of the cholangioscope into the CBD was possible after gentle dilatation of the proximal part of the tract, and the stone was visualized in the distal part of the CBD ( $\mathbf{F i g} \cdot \mathbf{3}$ ). Electrohydraulic lithotripsy was performed under direct visualization with pulverization of the stone (> Fig. 4; Video 1). A 10-Fr double-pigtail plastic stent was left in place for $24 \mathrm{~h}$ 


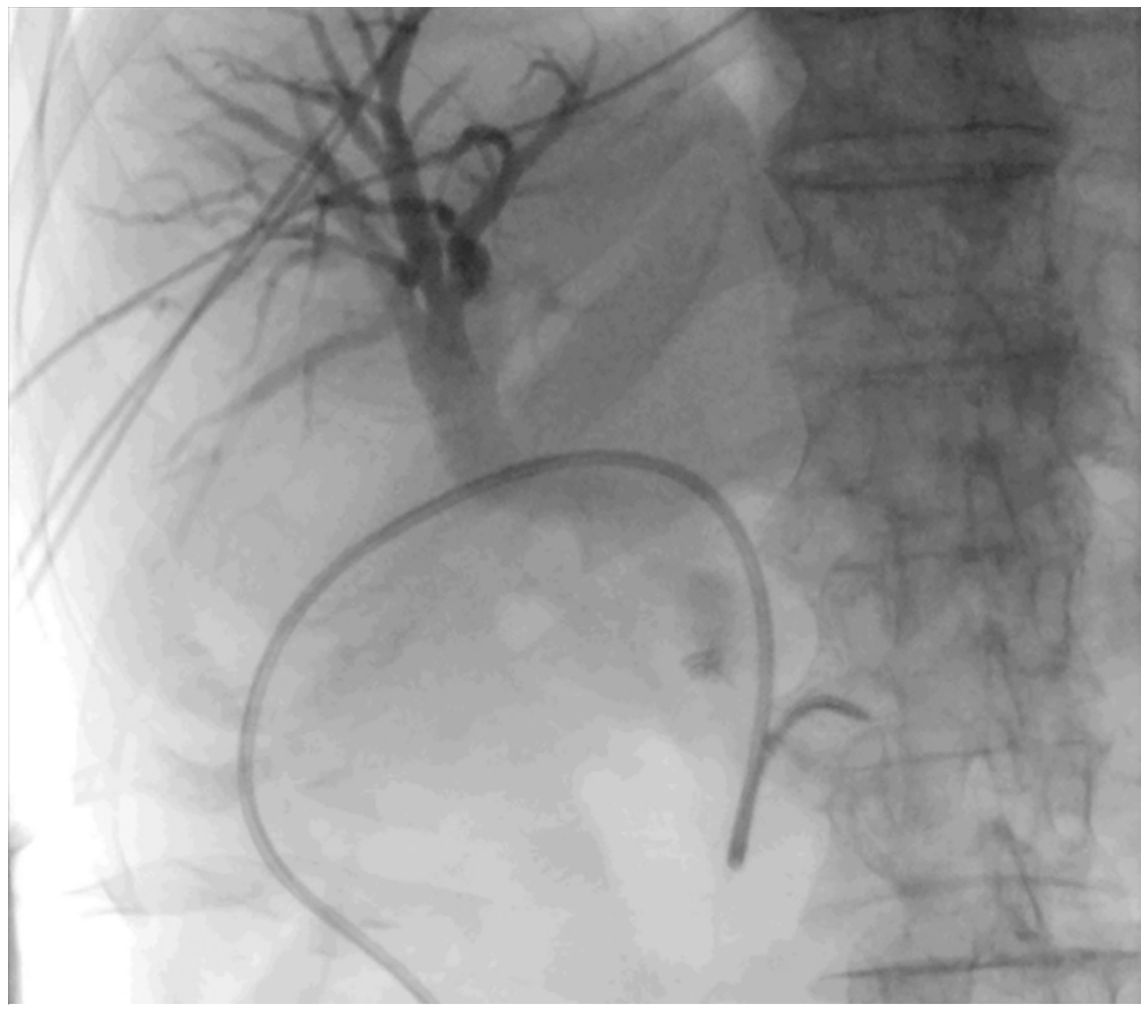

- Fig.5 Fluoroscopic image after placement of the 10-Fr double-pigtail plastic stent.

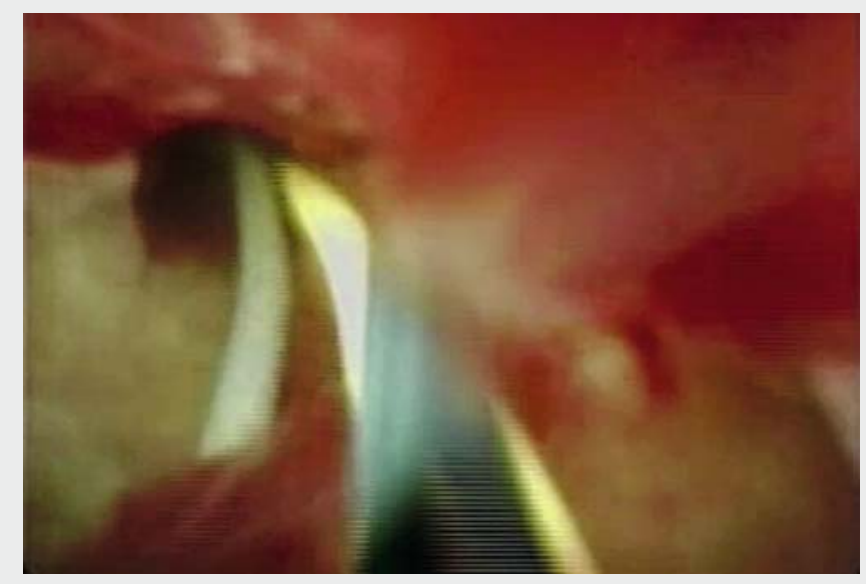

$\checkmark$ Video 1 Percutaneous transcystic cholangioscopy-guided electrohydraulic lithotripsy in a patient with altered surgical anatomy.

( Fig.5) to ensure easy access to the $\mathrm{CBD}$ in case of any complications. The patient remains well 1 month later.

Peroral endoscopic access to the biliary tree is difficult after surgical procedures which alter the upper gastrointestinal anatomy. Although there have been previous reports of percutaneous transhepatic cholangioscopy and lithotripsy [1,
Endoscopy_UCTN_Code_TTT_1AR_2AH

Competing interests

The authors declare that they have no conflicts of interest.

The authors

\section{Eduardo Rodrigues-Pinto, Pedro Pereira, Guilherme Macedo}

Gastroenterology Department, Centro Hospitalar São João, Porto, Portugal

\section{Corresponding author}

\section{Eduardo Rodrigues-Pinto, MD}

Gastroenterology Department, Centro Hospitalar São João, Alameda Prof. Hernâni Monteiro, 4200-319 Porto, Portugal

Fax: +351-22-5513601

edu.gil.pinto@gmail.com

\section{References}

[1] Hubers ], Patel R, Dalvie P et al. Percutaneous transhepatic cholangioscopy with electrohydraulic lithotripsy in a patient with choledocholithiasis complicating a benign stricture. VideoGIE 2019; 4: 423-425

[2] Anjum MR, Dyer J, Curran F et al. Cholangioscopy-guided electrohydraulic lithotripsy of a large bile duct stone through a percutaneous T-tube tract. VideoGIE 2018; 3 : 390-391

[3] Yeh YH, Hwang MH, Yang JC et al. Percutaneous transcystic cholangioscopy for combined treatment of gallbladder and bile duct stones. Endoscopy 1993; 25: 518-522

[4] Alabraba E, Travis S, Beckingham I. Percutaneous transhepatic cholangioscopy and lithotripsy in treating difficult biliary ductal stones: Two case reports. World ] Gastrointest Endosc 2019; 11: 298-307

\section{Bibliography}

Endoscopy 2020; 52: E392-E393

DOI 10.1055/a-1144-2490

ISSN 0013-726X

published online 17.4 .2020

(c) 2020. Thieme. All rights reserved.

Georg Thieme Verlag KG, Rüdigerstraße 14, 70469 Stuttgart, Germany 